\title{
The effect of various levels of fructose in a copper-deficient diet on Cu deficiency in male rats
}

\author{
BY CHARLES G. LEWIS ${ }^{1}$, MEIRA FIELDS ${ }^{1,2,3}$ AND TODD BEAL \\ ${ }^{1}$ Carbohydrate Nutrition Laboratory and ${ }^{2}$ Vitamin and Mineral Nutrition Laboratory, Beltsville \\ Human Nutrition Research Center, Agricultural Research Service, U.S. Department of Agriculture, \\ Beltsville, Maryland 20705, USA \\ ${ }^{3}$ Georgetown University Medical School, Washington DC 20007, USA \\ ${ }^{4}$ University of Maryland, College Park, Maryland 20742, USA
}

(Received 6 March 1989 - Accepted 28 September 1989)

\begin{abstract}
The present study was designed to examine the effects of various levels of fructose in a copper-deficient diet on some of the signs of $\mathrm{Cu}$ deficiency in the rat. Weanling male rats were randomly assigned to one of five diets which contained $0.6 \mu \mathrm{g} \mathrm{Cu} / \mathrm{g}$ diet and $627 \mathrm{~g}$ carbohydrate $/ \mathrm{kg}$ which was $(\mathrm{g} / \mathrm{kg}): 627$ fructose (diet 100); 470 fructose, 157 starch (diet 75); 313.5 fructose, 313.5 starch (diet 50); 157 fructose, 470 starch (diet 25); or 627 starch (diet 0). Rats ate their respective diets for either 2 or 5 weeks. There was a significant linear inverse response of body-weight $(P<0.0001)$, packed cell volume $(P<0.0001)$ and erythrocyte superoxide dismutase $(E C$ 1.15.1.1) activity $(P<0.008)$ to increasing levels of dietary fructose and a direct linear response of plasma cholesterol $(P<0.05)$ and blood urea nitrogen concentrations $(P<0.001)$ to increasing levels of dietary fructose. Liver, kidney and pancreatic $\mathrm{Cu}$ concentrations decreased in a dose-response manner as the level of dietary fructose increased. In general, if fructose was included in the diet the signs of $\mathrm{Cu}$ deficiency were exacerbated in a dose-response manner.
\end{abstract}

Copper deficiency : Fructose : Rat

Fructose is a naturally occurring monosaccharide which is normally present in the diet in small amounts. Before 1970 , most of the dietary fructose consumed in industrialized societies was provided as a component of sucrose which made up approximately $18 \%$ of the US diet (Page \& Friend, 1974). High-fructose maize sweeteners (HFMS) were introduced in 1970 and since that time the amount of fructose in foods in the US diet has increased sixfold (United States Department of Agriculture (USDA), 1984). HFMS are replacing sucrose in processed foods and in 1982 HFMS provided $48 \%$ of total energy sweeteners in processed foods, $53 \%$ in beverages and $61 \%$ in canning (Barry, 1983). As the amount of fructose in the US diet increases significantly above that which occurs in a normal or natural diet, it is necessary to examine potential effects of fructose consumption on the health of the general public.

The interaction of dietary fructose with copper has received considerable attention. Dietary fructose, when compared with starch, enhances the severity of the signs of $\mathrm{Cu}$ deficiency in male rats (Fields et al. 1983, 1984b; Reiser et al. 1983). Although caution should be used when extrapolating findings from rat studies to humans, these observations may have practical significance since the Food and Nutrition Board of the National Academy of Sciences (NAS) has estimated that the safe and adequate daily intake of $\mathrm{Cu}$ for humans is 2-3 mg (NAS, 1980). In the US, the daily intake of Cu from the diet has been estimated at $1 \mathrm{mg}$ or less (Holden et al. 1979; Klevay et al. 1979). Thus, it would appear 
that the current dietary practices in the US in relation to fructose and $\mathrm{Cu}$ should be of concern to nutritionists and to other people in the health professions.

In rodent studies in which dietary fructose was the dietary carbohydrate of a $\mathrm{Cu}$-deficient diet, the amount of fructose used in the diets was generally very high and results from the studies could be criticized on the grounds that the US population does not consume dietary fructose at the levels used in the studies. In light of this criticism and in view of the increasing amounts of fructose in US foods, we have investigated the effects of a diet low in $\mathrm{Cu}$ with various levels of fructose on some of the signs of $\mathrm{Cu}$ deficiency in the rat.

\section{MATERIALS AND METHODS}

Weanling male Sprague-Dawley rats were housed in quarters maintained at $20^{\circ}$ and $55 \%$ relative humidity with a reversed cycle of $12 \mathrm{~h}$ of light and $12 \mathrm{~h}$ of dark. Rats were randomly assigned to one of five diets which contained $627 \mathrm{~g}$ carbohydrate $/ \mathrm{kg}$ which comprised $627 \mathrm{~g}$ fructose $/ \mathrm{kg}$ (diet 100), $470 \mathrm{~g}$ fructose and $157 \mathrm{~g}$ starch $/ \mathrm{kg}$ (diet 75), 313.5 g fructose and $313.5 \mathrm{~g} \mathrm{starch} / \mathrm{kg}$ (diet 50 ), $157 \mathrm{~g}$ fructose and $470 \mathrm{~g}$ starch $/ \mathrm{kg}$ (diet 25) or $627 \mathrm{~g}$ starch $/ \mathrm{kg}$ (diet 0 ). Some rats were assigned to a diet which contained sucrose as the carbohydrate for comparison with diet 50 since both diets are identical in composition but contain fructose and glucose in different forms. All these $\mathrm{Cu}$-deficient diets contained 0.64 (SE $0 \cdot 02) \mu \mathrm{g} \mathrm{Cu} / \mathrm{g}$ diet (twelve determinations) by atomic absorption spectrophotometry. Some rats were also assigned to $627 \mathrm{~g}$ starch, sucrose or fructose $/ \mathrm{kg}$ diets with $6.0 \mu \mathrm{g} \mathrm{Cu} / \mathrm{g}$ diet to serve as controls for adequate dietary $\mathrm{Cu}$ intake. All diets contained the following ingredients $(\mathrm{g} / \mathrm{kg}$ diet): 627 carbohydrate, $200 \mathrm{egg}$ white solids, 95 maize oil, 30 nonnutritive fibre (cellulose), $35 \mathrm{Cu}$-free AIN-76 salt mix (American Institute of Nutrition (AIN), 1977) (formulated in our laboratory to omit cupric carbonate), 10 AIN-76A vitamin mix (AIN, 1980) supplemented with $2 \mathrm{mg}$ biotin and $2.7 \mathrm{~g}$ choline bitartrate. All rats had free access to diet and to distilled deionized drinking water.

Fasted rats were decapitated after consuming their respective diets for either 2 or 5 weeks. Blood was collected in heparinized tubes and centrifuged at $2500 \mathrm{rev} / \mathrm{min}$ at $5^{\circ}$ for $20 \mathrm{~min}$. Plasma was removed for the measurement of triacylglycerols (Megraw et al. 1979), cholesterol (Allain et al. 1974), uric acid (Praetorius \& Poulsen, 1953) and blood urea nitrogen (BUN) (Chaney \& Marback, 1962). Erythrocytes were washed once in 5 vol. cold saline ( $9 \mathrm{~g}$ sodium chloride/1), centrifuged and used for the determination of superoxide dismutase (EC 1.15.1.1; SOD) activity by the photochemical $o$-dianisidine riboflavin assay (Misra \& Fridovich, 1977). Standards and pooled, known laboratory controls were analysed with samples to verify accuracy. Blood collected in capillary tubes was centrifuged for the determination of packed cell volume.

Liver, heart, kidney and pancreas were removed quickly, trimmed free of fat and connective tissue and weighed. Tissue and diet $\mathrm{Cu}$ were extracted from samples by a method combining dry heat and acid digestion (Hill et al. 1986). Duplicate samples were analysed by flame atomic absorption spectrophotometry (Perkin-Elmer Model 5000; Perkin-Elmer, Inc. 1976). National Bureau of Standard Reference Material, bovine liver 1577 a, was digested and analysed along with samples to verify accuracy.

Values were analysed by computer using the SAS software system for data analysis (SAS Institute Inc., 1985). The main question asked was: what is the relation between the amount of fructose in the diet and the rats' response? Therefore, orthogonal contrasts were used to determine the fructose concentration effect which was partitioned into components due to linear, quadratic, cubic and quartic regression at weeks 2 and 5. Once a significant linear trend was established, all dietary fructose levels within the range of those used in this study are significantly different from one another in their effects. Contrasts and interactions of 
$P<0.05$ or less were considered statistically significant. Statistically significant curvilinear trends were not seen. Thus, only the linear component and its interaction is given in the Tables.

\section{RESULTS}

Body-weight of weanling rats at the beginning of the study was 58 (SE 6) g. Food intake was measured only in the diet $0(627 \mathrm{~g}$ starch $/ \mathrm{kg})$ and diet $100(627 \mathrm{~g}$ fructose $/ \mathrm{kg})$ groups. Food intake at both 2 and 5 weeks was about 14 (SE 3) and 11 (SE 2) g/d for the 0 and 100 fructose groups respectively. Growth of rats in the 100 fructose group was retarded when compared with the 0 fructose group (Table 1$)$ but relative food intake $(\mathrm{g} / \mathrm{kg}$ body-wt) was similar for the two groups. Thus, it is not clear whether the 100 fructose diet rats were smaller because they ate less as a consequence of the fructose $\mathrm{Cu}$ interaction, or whether they ate less because they were smaller rats. Food efficiencies (weight gain $(\mathrm{g}) \times 100 /$ energy consumed (kJ) were 3.6 (SE 0.2) and 3.0 (SE 0.2) at week 2, and 2.1 (SE 0.1) and 1.1 (SE 0.1) at week 5 , for the 0 and 100 fructose groups respectively. Thus, a partial explanation for retarded growth in the 100 fructose group is that these rats were less efficient in conversion of feed to body mass. Food intake and feed efficiency of the 0 fructose group were not significantly different from the values for rats eating starch, sucrose or fructose diets that were adequate in $\mathrm{Cu}$.

Table 1 gives the body-weights and tissue sizes of rats consuming various levels of dietary fructose and starch for either 2 or 5 weeks. There was a statistically significant difference $(P<0.0001)$ between body-weights of rats eating different levels of dietary fructose. The statistical relationship between dietary fructose level and body-weight as tested by fructose contrasts was linear and inverse, as rats that consumed higher dietary levels of fructose had lower body-weights at week 5. The length of time that the rats ate fructose was an important variable since there was a statistically significant $(P<0.004)$ greater apparent inverse response of body-weight to dietary fructose at 5 weeks than at 2 weeks. The bodyweights at week 5 of the starch, sucrose and fructose dietary groups that received adequate $\mathrm{Cu}$ intake were 287 (SE 8), 292 (SE 9) and 262 (SE 9) respectively (values not shown).

There was a significant inverse response of relative pancreatic size to different levels of dietary fructose at week $5(P<0.0001)$. Relative liver $(P<0.0001)$ and kidney $(P<0.002)$ sizes increased directly in relationship to the level of fructose in the diet. Relative heart size increased directly in relation to the level of fructose in the diet at week 5 , but not at week $2(P<0.001)$. Rats that received adequate dietary $\mathrm{Cu}$ with starch, sucrose or fructose had mean relative liver, heart, kidney and pancreatic sizes of 2.88 (SE 0.11), 0.34 (SE 0.01), 0.72 (SE 0.03 ) and 0.42 (SE 0.03 ) respectively at week 5 (values not shown).

Blood chemistry of rats consuming different levels of dietary fructose and starch is given in Table 2. There was a statistically significant inverse linear response of both packed cell volume $(P<0.0001)$ and erythrocyte SOD activity $(P<0.008)$ at week 5 but not at week 2 to different levels of dietary fructose. There was a direct linear response of both cholesterol $(P<0.05)$ and BUN concentrations $(P<0.0001)$ to various levels of dietary fructose at week 5 . Plasma triacylglycerol and uric acid concentrations were not significantly altered by the level of dietary fructose but both decreased from 2 weeks to 5 weeks. Blood chemistry of rats receiving adequate $\mathrm{Cu}$ with starch, sucrose or fructose was similar to the 0 fructose group with the exception of erythrocyte SOD activity which was 1145 (SE 95), 686 (SE 91) and 862 (SE 89) respectively at week 5 (values not shown).

Table 3 gives tissue $\mathrm{Cu}$ concentrations of rats consuming various levels of dietary fructose and starch. Liver and heart $\mathrm{Cu}$ concentrations were not affected by dietary fructose levels at 2 weeks but at 5 weeks there was a statistically significant inverse response of tissue 


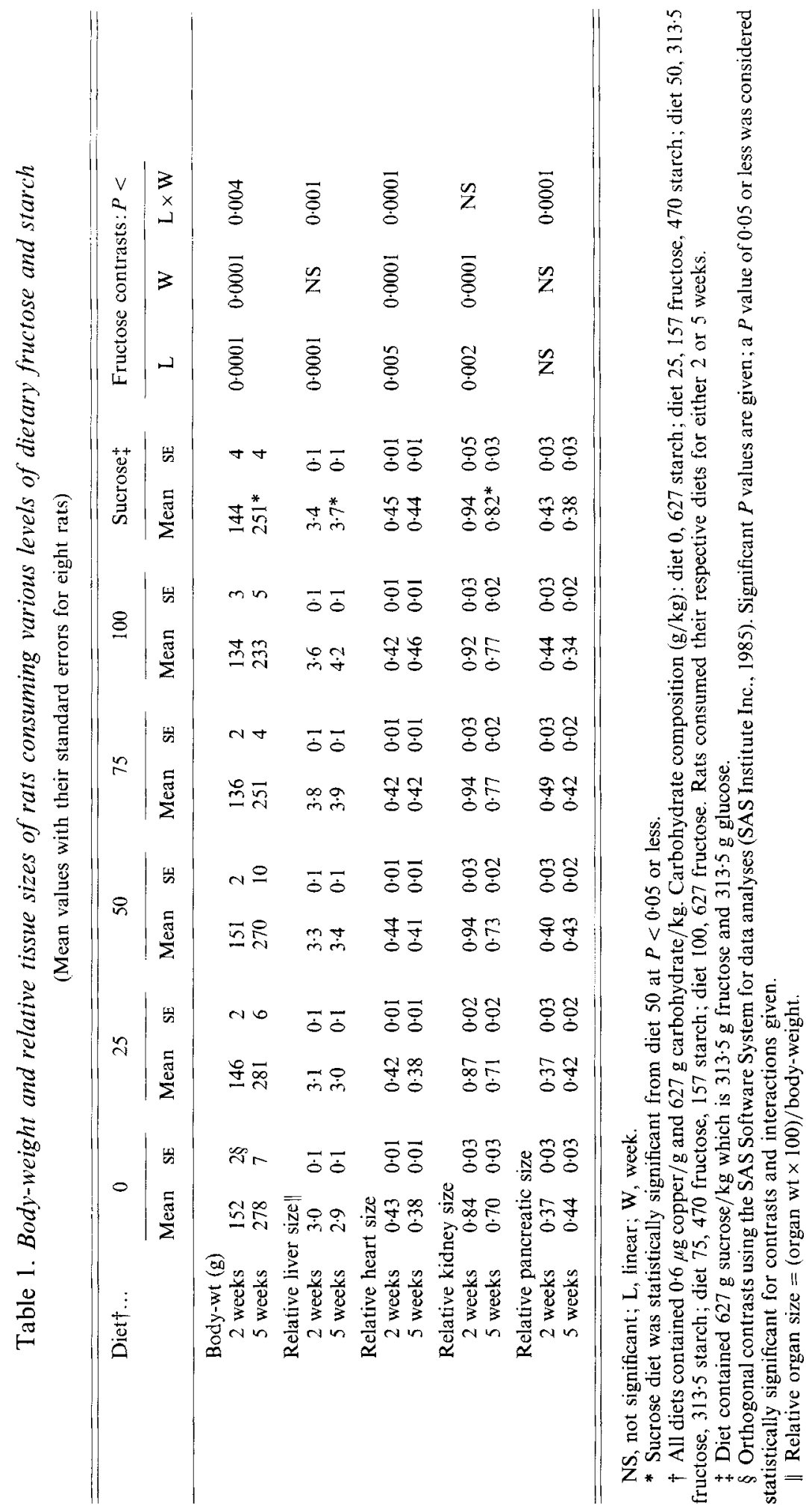


FRUCTOSE LEVELS AND COPPER DEFICIENCY

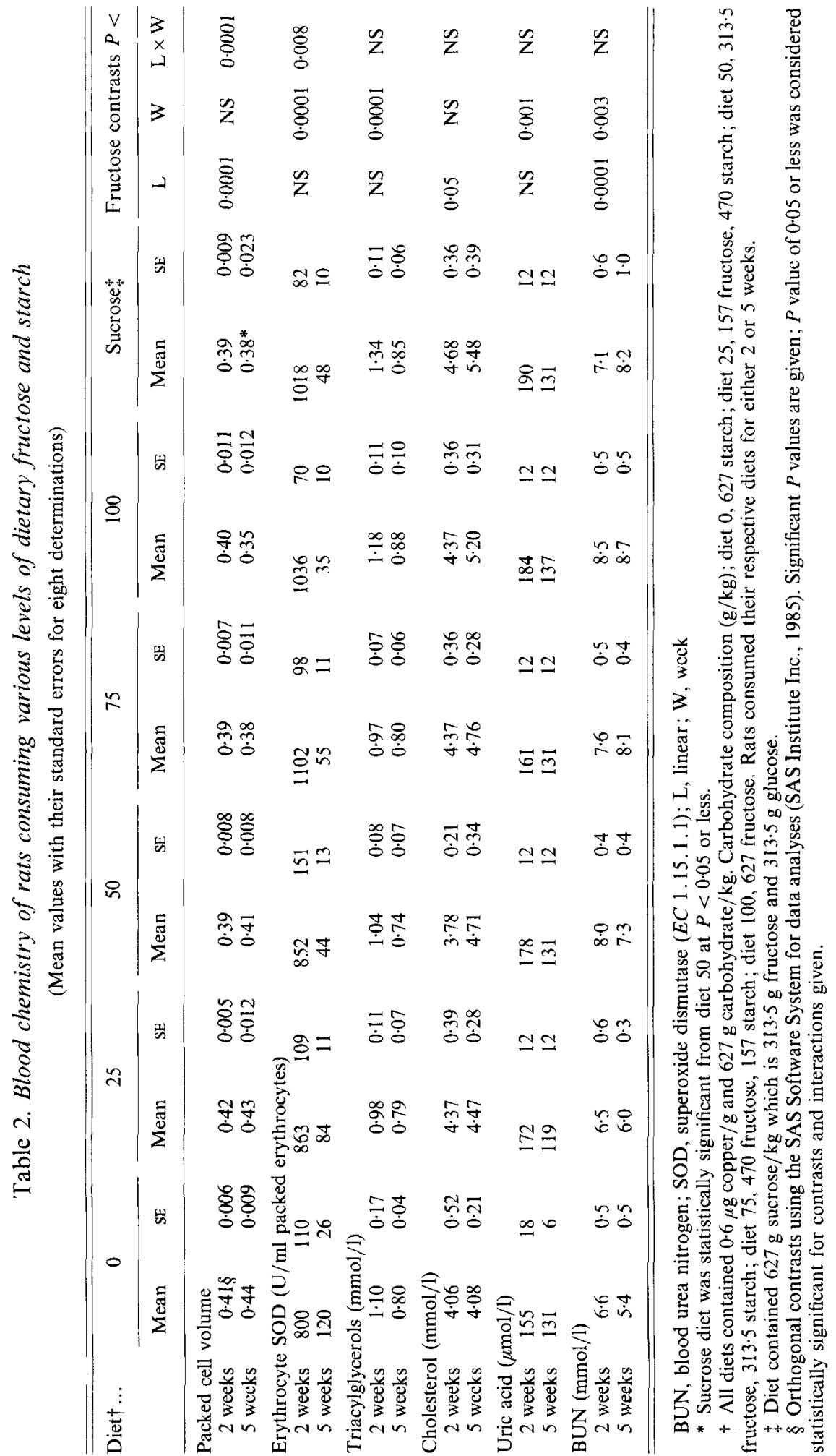




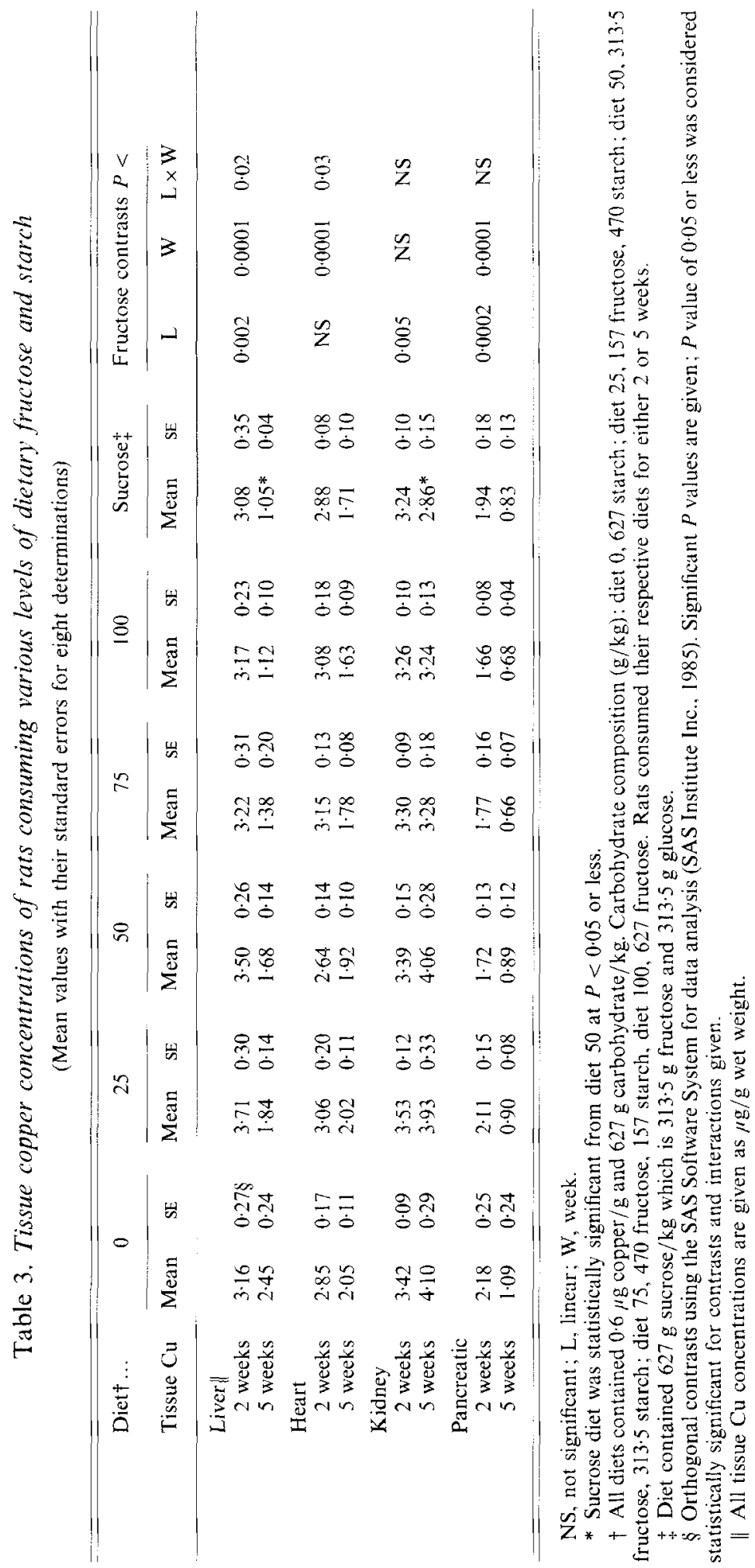


$\mathrm{Cu}(P<0.02)$ to dietary fructose. Kidney $\mathrm{Cu}$ concentrations did not change from 2 to 5 weeks. Pancreatic $\mathrm{Cu}$ concentration was inversely related to dietary fructose level $(P<$ 0.0002 ). Rats eating the starch, sucrose or fructose diets with adequate $\mathrm{Cu}$ had mean liver and heart $\mathrm{Cu}$ concentrations of 5.47 (SE 0.29) and 5.14 (SE 0.27) respectively at week 5 (values not shown). Kidney $\mathrm{Cu}$ concentrations of the starch, sucrose and fructose dietary groups with adequate $\mathrm{Cu}$ at week 5 were 6.41 (SE 0.48), 4.20 (SE 0.32) and 5.34 (SE 0.64) respectively and pancreatic $\mathrm{Cu}$ concentrations at week 5 were 1.61 (SE 0.13), 1.42 (SE 0.15) and 1.36 (SE 0.09) respectively (values not shown).

Sucrose is half glucose and half fructose, and rats consuming sucrose have been compared with rats eating diet $50(313.5 \mathrm{~g}$ starch and $313.5 \mathrm{~g}$ fructose $/ \mathrm{kg}$ diet $)$ in Tables 1-3. After consuming the sucrose diet for 5 weeks, body-weight, packed cell volume, liver $\mathrm{Cu}$ and kidney $\mathrm{Cu}$ concentrations were significantly $(P<0.05)$ lower, and liver and kidney sizes were greater $(P<0.05)$, when compared with rats eating diet 50 .

\section{DISCUSSION}

The purpose of the present study was to answer the following question: when dietary $\mathrm{Cu}$ intake is low, does increasing dietary fructose consumption exacerbate the signs of $\mathrm{Cu}$ deficiency in a dose-response manner? The 0 fructose diet contained starch as the source of carbohydrate and the starch was replaced with fructose at different levels until fructose was the only source of carbohydrate. Since the intermediate diets contained starch and fructose together at various levels the argument could be made that any adverse fructose effects were modulated by protective effects of starch. The present study was not designed to separate these possibilities. Historically, starch has been a major carbohydrate component of the diet. Starch consumption has not increased over a relatively short period of time, and because starch has been a major component of the diet for a long time the amount of starch consumed has been considered safe and adequate. Conversely, fructose has, in the past, been a minor carbohydrate component of the diet, but over a relatively short period of time fructose consumption has increased sixfold (USDA, 1984). Since human populations have not normally consumed relatively large amounts of fructose the potential health consequences of increased dietary fructose consumption should be tested for direct or indirect effects.

Our diets contained $627 \mathrm{~g}$ carbohydrate $/ \mathrm{kg}$ which accounted for $60 \%$ of total dietary energy. In the diet with the least amount of fructose, $157 \mathrm{~g} / \mathrm{kg}, 15 \%$ of energy came from fructose. At this level of fructose, and after consuming the diet for 5 weeks, erythrocyte SOD activity and liver $\mathrm{Cu}$ concentration were decreased when compared with the diet containing no fructose. In addition to these changes, there was some liver and heart enlargement in relation to body-weight, an increase in serum BUN concentration and a decrease in liver $\mathrm{Cu}$ concentration with diet $50 \mathrm{in}$ which fructose provided $30 \%$ of dietary energy. In diet 25 , although there was three times as much dietary starch as fructose, the inclusion of siarch did not completely inhibit some of the effects of fructose. Interestingly, of the total of thirty measurements made in the present study (fifteen variables at 2 different weeks) six from the sucrose group were significantly worse than the diet 50 fructose group even though both diets contained equal amounts of glucose and fructose.

In the US population, estimates of dietary sucrose consumption from naturally occurring and added sources is approximately $15-20 \%$ of total energy intake (Glinsmann et al. 1986). Since sucrose is $50 \%$ fructose, the total consumption of dietary fructose by the US population is about $10 \%$ of total energy. This estimated fructose consumption lies below the diet 25 (15\% of total energy) which was the lowest level of fructose used in the present study. It should be pointed out that the $10 \%$ of total energy value is an average fructose 
intake estimate and that many individuals, particularly teenagers, consume fructose in the range of $15 \%$ of total energy (Frank et al. 1978; Powers, 1978). If applicable to humans, our findings provide legitimate reasons for concern about the increasing fructose consumption by people of industrialized societies beyond that which occurs naturally in foods.

The findings of the present study clearly indicate that the severity of some of the signs attributed to nutritional $\mathrm{Cu}$ deficiency were related to the level of fructose in the diet. Although all the diets contained the same concentration of $\mathrm{Cu}$, as the level of fructose was increased in the diet the packed cell volume, erythrocyte SOD activity, and liver, kidney and pancreatic $\mathrm{Cu}$ concentrations decreased in a dose-response manner. Time was an important factor for some responses to the fructose- $\mathrm{Cu}$ interaction. For example, erythrocyte SOD activity was actually higher with higher levels of dietary fructose at 2 weeks but lower with higher levels of fructose at 5 weeks. We suggest that the SOD activity pattern seen at 2 weeks may represent short-term adaptation when essential functions are maintained or even enhanced while nonessential functions (growth) are curtailed. The SOD activity pattern at 5 weeks may represent long-term adaptation when the animal is no longer capable of maintaining certain essential functions.

Although it may be perilous to extrapolate findings and conclusions from rat studies to humans, the fructose- $\mathrm{Cu}$ interaction observed in rats has relevance to humans. A study (Reiser et al. 1985) which was designed to provide twenty-four male volunteers with a diet containing $20 \%$ of energy as fructose and $1 \mathrm{mg} \mathrm{Cu} / \mathrm{d}$ for 14 weeks was terminated prematurely at 11 weeks because four of the subjects developed heart-related abnormalities which included one coronary infarct, two incidences of severe tachycardia and one occurrence of extrasystolic beats. In addition, the activity of the erythrocyte enzyme SOD was significantly reduced in subjects consuming the low- $\mathrm{Cu}$ diet containing fructose as compared with starch. These observations are in agreement with the present study in which erythrocyte SOD activity was significantly lower in rats eating fructose as compared with starch and in which heart weights of fructose-fed rats were the same although body-weights were smaller than starch-fed rats. Male rats fed on a low-Cu, fructose diet (Fields et al. 1983) eventually die as a result of enlarged hearts which rupture at the apex.

We do not know why the signs of $\mathrm{Cu}$ deficiency are related to the level of fructose in the diet or what is (are) the mechanism(s) of the fructose effect on $\mathrm{Cu}$ deficiency. Findings from the present study showed that fructose in the diet resulted in lower tissue concentrations of $\mathrm{Cu}$. Failla et al. (1988) have suggested that fructose has a differential effect on one or more processes of $\mathrm{Cu}$ metabolism since the dietary requirement for $\mathrm{Cu}$ to maintain the immune system was higher in rats consuming fructose as compared with starch. With our present knowledge of $\mathrm{Cu}$ and fructose metabolism, it is not obvious how fructose might affect $\mathrm{Cu}$ metabolism.

BUN is used clinically as an indicator of protein catabolism. BUN concentration was directly related to the level of fructose in the $\mathrm{Cu}$-deficient diet and it has been suggested that accelerated protein catabolism is a reflection of the severity of $\mathrm{Cu}$ deficiency (Fields et al. 1984a) and is secondary to the Cu deficiency.

The findings of the present study show that how the rat responds to $\mathrm{Cu}$ deficiency depends on the presence and on the level of fructose in the diet. Fructose caused a more severe degree of $\mathrm{Cu}$ deficiency in a dose-response manner. Additional studies are needed to pinpoint and elucidate the mechanism(s) of the fructose effect on $\mathrm{Cu}$ deficiency. 


\section{REFERENCES}

Allain, C. C., Poon, L. S., Chan, C. S. G., Richmond, W. \& Fu, P. C. (1974). Enzymatic determination of total serum cholesterol. Clinical Chemistry 20, 470-475.

American Institute of Nutrition (1977). Report of the American Institute of Nutrition ad hoc Committee on standards for nutritional studies. Journal of Nutrition 107, 1340-1348.

American Institute of Nutrition (1980). Second report of the American Institute of Nutrition ad hoc Committee on standards for nutritional studies. Journal of Nutrition 110, 1726.

Barry, R. D. (1983). HFCS: A sweetener revolution. In National Food Review, vol. 23, pp. 10-13. Washington, DC: US Department of Agriculture Economic Research Service.

Chaney, A. L. \& Marback, E. P. (1962). Modified reagents for determination of urea and ammonia. Clinical Chemistry 8, 130-132.

Failla, M. L., Babu, U. \& Seidel, K. E. (1988). Use of immunoresponsiveness to demonstrate that the dietary requirement for copper in young rats is greater with dietary fructose than dietary starch. Journal of Nutrition $118,487-496$.

Fields, M., Ferretti, R. J., Reiser, S. \& Smith, J. C. Jr (1984a). The severity of copper deficiency in rats is determined by the type of dietary carbohydrate. Proceedings of the Society for Experimental Biology and Medicine 175, 530-537.

Fields, M., Ferretti, R. J., Smith, J. C. Jr \& Reiser, S. (1983). Effect of copper deficiency on metabolism and mortality in rats fed sucrose or starch diets. Journal of Nutrition 113, 1335-1345.

Fields, M., Ferretti, R. J., Smith, J. C. Jr \& Reiser, S. (1984b). The interaction of type of dietary carbohydrates with copper deficiency. American Journal of Clinical Nutrition 39, 289-295.

Frank, G. C., Berenson, G. S. \& Webber, L. S. (1978). Dietary studies and the relationship of diet to cardiovascular disease risk factor variables in 10-year-old children-The Bogalusa Heart Study. American Journal of Clinical Nutrition 31, 328-340.

Glinsmann, W. H., Irausquin, H. \& Park, Y. K. (1986). Evaluation of health aspects of sugar contained in carbohydrate sweeteners. Journal of Nutrition 116, S1-S216.

Hill, A. D., Patterson, K. Y., Veillon, C. \& Morris, E. R. (1986). Digestion of biological materials for mineral analysis using a combination of heat and dry ashing. Analytical Chemistry 58, 2340-2342.

Holden, J. M., Wolf, W. F. \& Mertz, W. (1979). Zinc and copper in self-selected diets. Journal of the American Dietetic Association 79, 23-28.

Klevay, L. M., Reck, S. \& Barcome, D. F. (1979). Evidence of dietary copper and zinc deficiencies. Journal of the American Medical Association 241, 1916-1918.

Megraw, R. E., Dunn, D. E. \& Biggs, H. G. (1979). Manual and continous-flow colorimetry of triacylglycerols by a fully enzymatic method. Clinical Chemistry 25, 273-278.

Misra, H. P. \& Fridovich, I. (1977). Superoxide dismutase: a photochemical augmentation assay. Archives of Biochemistry and Biophysics 181, 308-312.

National Research Council (1980). Recommended Dietary Allowances, 9th revised ed. Washington, DC: National Academy of Sciences.

Page, L. \& Friend, B. (1974). Levels of uses of sugars in the United States. In Sugar in Nutrition, pp. 93-107 [H. L. Sipple and K. W. McNutt, editors]. New York: Academic Press.

Perkin-Elmer Inc. (1976). Analytical Methods for Atomic Absorption Spectrophotometry. Norwalk, CT: PerkinElmer Inc.

Powers, H. W. S. Jr (1978). Sucrose consumption in our society. American Journal of Clinical Nutrition 31, 1301.

Praetorius, E. \& Poulsen, H. (1953). Enzymatic determination of uric acid with detailed instructions. Scandinavian Journal of Clinical Laboratory Investigation 5, 273-279.

Reiser, S., Ferretti, R. J., Fields, M. \& Smith, J. C. Jr (1983). Role of dietary fructose in the enhancement of mortality and biochemical changes associated with copper deficiency in rats. American Journal of Clinical Nutrition 38, 214-222.

Reiser, S., Smith, J. C. Jr. Mertz, W., Holbrook, J. T., Scholfield, D. J., Powell, A. S., Canfield, W. K. \& Canary, J. J. (1985). Indices of copper status in humans consuming a typical American diet containing either fructose or starch. American Journal of Clinical Nutrition 42, 242-251.

SAS Institute Inc. (1985). SAS User's Guide: Statistics, 5th ed., Cary, NC:SAS Institute Inc.

United States Department of Agriculture (1984). Sugar and sweeteners outlook and situation report. Economic Research Service Bulletin no. SSRV9N2. Washington, DC: United States Department of Agriculture. 